OPEN ACCESS

Edited by:

Igor B. Mekjavic,

JoŽef Stefan Institute, Slovenia

Reviewed by:

Beat Knechtle

University of Zurich, Switzerland

Stefanos Volianitis,

Aalborg University, Denmark

*Correspondence:

Marcelo Papoti

mpapoti@yahoo.com.br

Specialty section:

This article was submitted to

Exercise Physiology,

a section of the journal

Frontiers in Physiology

Received: 20 April 2017

Accepted: 19 September 2017

Published: 10 October 2017

Citation:

Campos EZ, Kalva-Filho CA,

Gobbi RB, Barbieri RA, Almeida NP

and Papoti M (2017) Anaerobic

Contribution Determined in Swimming

Distances: Relation with Performance.

Front. Physiol. 8:755

doi: 10.3389/fphys.2017.00755

\section{Anaerobic Contribution Determined in Swimming Distances: Relation with Performance}

\author{
Eduardo Z. Campos ${ }^{1,2}$, Carlos A. Kalva-Filho ${ }^{3}$, Ronaldo B. Gobbi ${ }^{4}$, Ricardo A. Barbieri ${ }^{4}$, \\ Nayara P. Almeida ${ }^{4}$ and Marcelo Papoti ${ }^{2,3,4 *}$ \\ ${ }^{1}$ Nucleus of Investigation in Sport Performance, Department of Physical Education, Federal University of Pernambuco, \\ Recife, Brazil, ${ }^{2}$ Graduate Program in Motor Science, São Paulo State University, Rio Claro, Brazil, ${ }^{3}$ Graduate Program in \\ Rehabilitation and Functional Performance, São Paulo University, Ribeirão Preto, Brazil, ${ }^{4}$ School of Physical Education and \\ Sport, University of São Paulo, Ribeirão Preto, Brazil
}

Total anaerobic contribution (TAn) can be assessed by accumulated oxygen deficit, and through sum of glycolytic and phosphagen contribution which enable the evaluation of TAn without influences on mechanical parameters. However, little is known about the difference of TAn within swimming distances. Therefore, the objectives of the present study were to determine and compare the TAn in different performances using the backward extrapolation technique and amount of lactate accumulated during exercise, and relate it with swimming performance. Fourteen competitive swimmers performed five maximal front crawl swims of 50, 100, 200, 400, and $800 \mathrm{~m}$. The total phosphagen (AnAl) and glycolytic (AnLa) contributions were assumed as the fast component of post-exercise oxygen consumption (EPOC FAST $_{\text {) }}$ and amount of blood lactate accumulated during exercise, respectively. TAn was the sum of AnAl and AnLa. Significantly lower values of AnLa were observed in the $800 \mathrm{~m}(p<0.01)$ than other distances. For AnAl, the $50 \mathrm{~m}$ performance presented the lowest values, followed by 100 and $800 \mathrm{~m}(p<0.01)$. The highest values of AnAl were observed in the 200 and $400 \mathrm{~m}(p>0.13)$. The TAn was significantly higher in the 200 and $400 \mathrm{~m}$ performances than observed at 50 and $800 \mathrm{~m}(p<0.01)$. Anaerobic contributions were correlated with 50, 100, 200, and $400 \mathrm{~m}$ performances $(p<0.01)$. The AnAl contribution was not correlated with $400 \mathrm{~m}$ performance. Anaerobic parameters were not correlated with $800 \mathrm{~m}$ performance. In conclusion, the highest values of anaerobic contribution were observed in the 200 and $400 \mathrm{~m}$ distances. Moreover, TAn is important to performances below $400 \mathrm{~m}$, and may be used in training routines.

Keywords: anaerobic capacity, swimming, performance, athletes, training

\section{INTRODUCTION}

Swimming performance depends on physiological (endurance capacity, and anaerobic fitness), technical, and morphological factors (Pelayo et al., 2007; Lätt et al., 2009; Kalva-Filho et al., 2015). In relation to physiological aspects, studies have demonstrated that both the aerobic and anaerobic metabolisms are important to swimming performance (Zamparo et al., 2000; Figueiredo et al., 2011; Kalva-Filho et al., 2015). Considering the large time volume expended during training to improve 
specific metabolisms, knowledge about energy balance in different performances is important for specific training prescription (Toussaint and Hollander, 1994).

Although the aerobic contribution seems to be easily calculated by the integral of oxygen consumption $\left(\mathrm{VO}_{2}\right)$ during the effort (Figueiredo et al., 2011), the determination of the anaerobic contribution is complex. In this context, the most accepted method to estimate anaerobic contribution is the accumulated oxygen deficit (AOD), which is assumed as the difference between oxygen demand and aerobic contribution during an effort (Reis et al., 2010a,b; Kalva-Filho et al., 2016). However, at least three limitations may decrease its applicability for swimmer evaluations.

The first limitation is the time expended to determinate the oxygen demand, which requires several submaximal efforts performed on different days and at different intensities, decreasing the applicability of this method during training routines. The second limitation is that total phosphagen (AnAl) and glycolytic (AnLa) contributions cannot be determined separately using the AOD method, decreasing the possible investigation of these metabolisms in different swimming distances. Finally, the third limitation is the use of a snorkel and valve system to assess $\mathrm{VO}_{2}$ during swimming (Reis et al., 2010a,b), which reduces the speed and clearly disrupts the motor pattern, making undulations, turns, and side respiration impossible during the effort (Jalab et al., 2011; Campos et al., 2016). Considering the importance of these mechanical factors, the use of a snorkel and valve system could influence the AOD values and, consequently, lead to misinterpretation of the importance of the anaerobic metabolism in different performances.

In cycling, Bertuzzi et al. (2010) showed that AOD can be determined by the sum of $\mathrm{AnAl}$, assumed as the fast component of post-exercise oxygen consumption (EPOC $\mathrm{FAST}_{\mathrm{F}}$ ), and AnLa, determined through the amount of blood lactate accumulated during exercise. These results have been confirmed by other authors (Zagatto et al., 2016a), allowing the use of this method in several modalities (Bertuzzi et al., 2015; Milioni et al., 2016; Zagatto et al., 2016b). Besides the determination of two anaerobic components, another advantage is the assessment of $\mathrm{VO}_{2}$ only after exercise, which eliminates the use of a snorkel and valve system.

In this context, the backward extrapolation technique consists of connecting the swimmer to a gas analyzer as quickly as possible after exercise (Montpetit et al., 1981; Costill et al., 1985). VO $(\log$ transformed) and recovery time are linearly adjusted and $\mathrm{VO}_{2}$ relative to the effort is determined at the end of exercise (Campos et al., 2016). Although the majority of studies have used the backward extrapolation technique in the first $30 \mathrm{~s}$ of recoveryassessing peak oxygen consumption $\left(\mathrm{VO}_{2 \mathrm{PEAK}}\right.$ ) (Kalva-Filho et al., 2015; Campos et al., 2016) — the time of monitoring can be extended, allowing its use to determine EPOC $_{\mathrm{FAST}}$ (i.e., AnAl) (Kalva-Filho et al., 2015).

The advantages of determining anaerobic contributions through the sum of $\mathrm{AnAl}$ and $\mathrm{AnLa}$, is maintaining the ecological validity of measurements, consequently increasing the applicability of results. However, as well as this parameter being frequently ignored in energy balance in swimming, few studies have used the backward extrapolation technique to determine AnAl values (Kalva-Filho et al., 2015). In addition, although these parameters have been extensively used to characterize different efforts, their comparison between different swimming distances, and the correlations of $\mathrm{AnAl}$ and AnLa with different swimming distances are scarce in swimming (Kalva-Filho et al., 2015). Thus, the objectives of the present study were to determine and compare the AnAl and AnLa in different swimming distances (50-800 $\mathrm{m}$ ), using the backward extrapolation technique and the net of lactate appearance during exercise, and relate them with performance. Our hypothesis was that TAn would increase with swimming distance except for $800 \mathrm{~m}$ that would elicit minor TAn due to greater aerobic contribution.

\section{MATERIALS AND METHODS}

\section{Participants}

Fourteen competitive swimmers (seven male and seven female; age: $18.85 \pm 3.18$ years; body mass: $69.05 \pm 12.3 \mathrm{~kg}$ ) with 4 years minimum experience in national level competitions, volunteered in the present study. They were recruited at a swimming team of national level of a local university. This study was carried out in accordance with the recommendations of Declaration of Helsinki, approved by the Committee of Ethical on Research of São Paulo State University. All participants or they parents were informed about the experimental procedures, risk and benefits, and gave written informed consent. Participants were only recruited if they were not currently taking chronic or daily doses of anti-inflammatory medication and they were instructed to avoid drinking caffeine, alcohol, and energy drinks for at least $12 \mathrm{~h}$ prior to each measurement.

\section{Experimental Design}

Swimmers performed five maximal front crawl swims of 50, 100, 200,400 , and $800 \mathrm{~m}$ with an interval of at least $24 \mathrm{~h}$ between each bout. After a rest of $5 \mathrm{~min}, \mathrm{VO}_{2}$ values at baseline were determined. Immediately after the efforts, a gas analyzer was connected to the swimmer (backward extrapolation technique) and $\mathrm{VO}_{2}$ was monitored during the first $5 \mathrm{~min}$ of recovery, to determine the EPOC ${ }_{\mathrm{FAST}}$. Blood lactate concentrations $\left(\left[\mathrm{La}^{-}\right]\right)$ were measured at baseline and during recovery, to establish the amount of accumulation.

Before each effort, a standardized warm up was performed consisting of $\sim 1,000 \mathrm{~m}$ front crawl at low to moderate intensity, determined subjectively by the swimmers. The evaluations were performed in a $25-\mathrm{m}$ swimming pool with water temperature of $26 \pm 1^{\circ} \mathrm{C}$. Expired gases were collected breath-by-breath (Quark PFT; Cosmed ${ }^{\circledR}$, Rome, Italy). The gas analyzer was calibrated immediately before and verified after each test using a certified gravimetrically determined gas mixture. The ventilometer was calibrated pre-exercise and verified postexercise using a $3 \mathrm{~L}$ syringe in accordance with the manufacturer's instructions. Following removal of outliers to exclude discrepant breaths, breath-by-breath data were interpolated (OriginPro 8.0, OriginLab Corporation, Microcal, Massachusetts, USA) to enhance the underlying responsive characteristics. Blood samples $(25 \mu \mathrm{L})$ obtained from the ear lobe were used to determinate $\left[\mathrm{La}^{-}\right]$(YSI-2300; Yellow Springs Instruments ${ }^{\circledR}$, Ohio, USA). 
Time of each effort was assessed manually through a digital chronometer (Casio, HS-70 W). Average speed was calculated by dividing distance by time of each bout.

\section{Backward Extrapolation Technique and Blood Lactate Accumulation}

After each effort, athletes were instructed to breathe immediately into a face mask (Hans Rudolph, Kansas City, MO, USA), connected to a breath-by-breath gas analyzer system (Quark PFT, Cosmed ${ }^{\circledR}$, Rome, Italy). $\mathrm{VO}_{2}$ values were log-transformed and plotted against time, which was linearly adjusted. Thus, the yintercept was considered as $\mathrm{VO}_{2}$ at the end of exercise (Montpetit et al., 1981; Bonne et al., 2014; Kalva-Filho et al., 2015; Campos et al., 2016), and assumed as the first point of recovery.

To calculate the amount of blood lactate accumulation, the $\left[\mathrm{La}^{-}\right]$was determined at baseline and the 3rd, 5, and 7 th min during recovery. The $\left[\mathrm{La}^{-}\right]$at peak was measured during recovery and assumed as the highest value observed. The accumulation was the difference between $\left[\mathrm{La}^{-}\right]$at peak and baseline values $\left(\Delta\left[\mathrm{La}^{-}\right]\right)$.

\section{Anaerobic Contributions}

To calculate the EPOC $\mathrm{FAST}_{\mathrm{T}}$ values, $\mathrm{VO}_{2}$ during $5 \mathrm{~min}$ of recovery was adjusted by a bi-exponential decay fit (OriginPro 8.0, OriginLab Corporation, Microcal, Massachusetts, USA) (Bertuzzi et al., 2010; Zagatto et al., 2011; Kalva et al., 2015). Amplitude and time constant of the first exponential decay was determined and the product of these two variables was assumed as the EPOC $_{\mathrm{FAST}}$ or AnAl contribution (Bertuzzi et al., 2010; Zagatto et al., 2011; Kalva et al., 2015). AnLa was determined by the $\Delta\left[\mathrm{La}^{-}\right]$, considering a metabolic equivalent of $3 \mathrm{~mL} \cdot \mathrm{O}_{2} \cdot{ }^{-1}$ $\mathrm{kg}^{-1}$ for each unit of lactate accumulated during the maximal effort (Zamparo et al., 2000). This metabolic equivalent has previously been used in swimming to determine AnLa (Zamparo et al., 2011; Kalva-Filho et al., 2015).

\section{Statistical Analysis}

The normality of data was previously confirmed using the Shapiro-Wilk's test, allowing presentation of data as mean \pm standard deviation $(S D)$. Mauchly's sphericity test was also applied, allowing the use of parametric statistics. The anaerobic parameters in different performances were compared through analysis of variance (ANOVA) for repeated measurements, followed by Tukey's post-hoc test. Pearson's correlation was used to test the relations between anaerobic parameters and performances in different distances. The correlation coefficient was classified as very small (0.00-0.19), small (0.20-0.39), moderate (0.40-0.69), strong (0.70-0.89), and very strong $(0.90-$ 1.00). For all analysis, the Statistical Package for Social Science software, version 17.0 (SPSS Inc, Chicago, Illinois) was used and the level of significance was $p<0.05$.

\section{RESULTS}

Performance times in 50,100, 200, 400, and $800 \mathrm{~m}$ were $28.7 \pm$ $2.6,64.3 \pm 4.8,137.2 \pm 10.7,292.1 \pm 18.6$, and $604.9 \pm 45.6 \mathrm{~s}$, respectively.
Parameters for anaerobic contribution determination in the different performances are demonstrated in Table 1. For AnAl parameters, the $50 \mathrm{~m}$ performance demonstrated the lowest values of amplitude $(p<0.001)$. On other hand, the highest values of time constant were observed after 50 and $200 \mathrm{~m}$ ( $p$ $<0.001)$. Although similar values for $\left[\mathrm{La}^{-}\right]$at baseline were observed $(p>0.08)$, peak values were lower after 50 and $800 \mathrm{~m}$ performances $(p<0.02)$. The lowest values of lactate accumulation were observed in the $800 \mathrm{~m}$ performance $(p<0.03)$ (Table 1).

Figure 1 demonstrates the $\mathrm{AnAl}$ and AnLa contributions in different performances. The AnLa contribution in the $800 \mathrm{~m}$ performance was significant lower than the 200 and $400 \mathrm{~m}$ performances $(p<0.01)$. No differences were observed between $50,100,200$, and $400 \mathrm{~m}$ performances $(p>0.06)$. For AnAl contribution, values observed in the $50 \mathrm{~m}$ performance were significantly lower than in the 200 and $400 \mathrm{~m}$ performances $(p<0.01)$. No significant differences were observed between the longest performances $(p>0.13)$. Figure 2 demonstrates the total anaerobic contribution observed in different performances. No differences were observed between 100, 200, and $400 \mathrm{~m}$ performances $(p>0.70)$. The lowest values were observed during the 50 and $800 \mathrm{~m}$ performances, with no differences between these efforts $(p=0.20)$.

Table 2 demonstrates the correlations between physiological parameters and performances. Anaerobic contributions were correlated with 50, 100, and $200 \mathrm{~m}$ performances $(p<$ 0.01 ). The AnAl contribution was not correlated with $400 \mathrm{~m}$ performance. Anaerobic parameters were not correlated with $800 \mathrm{~m}$ performance.

\section{DISCUSSION}

The present study aimed to compare anaerobic contribution determined in different distances, and relate it with swimming performance. The main findings of the present study were that AnLa contribution was lower in $800 \mathrm{~m}$ than 200 and $400 \mathrm{~m}$, while no difference was found between 50, 100, 200, and $400 \mathrm{~m}$. In relation to $\mathrm{AnAl}, 100,200,400$, and $800 \mathrm{~m}$ did not present differences, and $\mathrm{AnAl}$ in the $50 \mathrm{~m}$ was significantly lower than in the 200 and $400 \mathrm{~m}$. The total anaerobic contribution was significantly higher in 100,200 , and $400 \mathrm{~m}$, however, the $100 \mathrm{~m}$ TAn was similar to $800 \mathrm{~m}$. Therefore, 200 and $400 \mathrm{~m}$ are the distances that present higher anaerobic contributions; both can be used to estimate the anaerobic capacity of swimmers, and also to assess changes arising from specific training. Finally, TAn can be assessed during swimming training periodization since it presents associations with performance (except $800 \mathrm{~m}$ ).

The anaerobic contribution has been demonstrated to be important for swimming performance (Figueiredo et al., 2011; Kalva-Filho et al., 2015), thus its evaluation has clear meaning. However, the main limitation of anaerobic contribution determination is the need for time consuming tests - AOD (Reis et al., 2010a,b; Kalva-Filho et al., 2016) performed with a snorkel, which reduces swimming speed (Jalab et al., 2011) and precludes undulations and turns. Therefore, 
TABLE 1 | Parameters for anaerobic contribution determination at different performances.

\begin{tabular}{|c|c|c|c|c|c|}
\hline & \multicolumn{5}{|c|}{ Performances } \\
\hline & $50 \mathrm{~m}$ & $100 \mathrm{~m}$ & $200 \mathrm{~m}$ & $400 \mathrm{~m}$ & $800 \mathrm{~m}$ \\
\hline \multicolumn{6}{|l|}{ AnAl } \\
\hline Amplitude (L. $\left.\min ^{-1}\right)$ & $2.0 \pm 0.8$ & $2.9 \pm 0.9^{a}$ & $2.9 \pm 0.7^{a}$ & $3.0 \pm 1.1^{\mathrm{a}}$ & $2.9 \pm 0.9^{a}$ \\
\hline Time constant (min) & $0.7 \pm 0.1$ & $0.6 \pm 0.1^{\mathrm{a}}$ & $0.8 \pm 0.2^{b}$ & $0.6 \pm 0.2^{\mathrm{ac}}$ & $0.6 \pm 0.1^{\mathrm{ac}}$ \\
\hline \multicolumn{6}{|l|}{ AnLa } \\
\hline$\left[\mathrm{La}^{-}\right]$at baseline $(\mathrm{mM})$ & $1.5 \pm 0.6$ & $1.7 \pm 0.5$ & $1.6 \pm 0.3$ & $1.9 \pm 0.6$ & $1.4 \pm 0.3$ \\
\hline$\left[\mathrm{La}^{-}\right]$at peak $(\mathrm{mM})$ & $9.9 \pm 2.4^{b}$ & $10.8 \pm 2.3^{a}$ & $12.2 \pm 3.1^{a}$ & $12.0 \pm 3.4^{a}$ & $7.8 \pm 2.4^{\mathrm{bdc}}$ \\
\hline$\left[\mathrm{La}^{-}\right]$accumulation (mM) & $8.4 \pm 2.4$ & $9.1 \pm 2.1$ & $10.6 \pm 3.3$ & $10.0 \pm 3.4$ & $6.3 \pm 2.5^{\mathrm{abdc}}$ \\
\hline
\end{tabular}

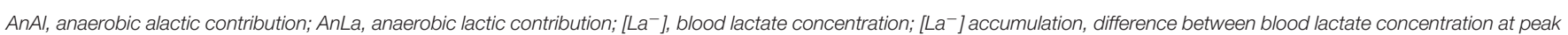
and baseline. ${ }^{a}$ Significantly different from $50 \mathrm{~m}$; ${ }^{b}$ Significantly different from $100 \mathrm{~m}$; ' Significantly different from $200 \mathrm{~m} ;{ }^{d}$ significantly different from $400 \mathrm{~m}$.
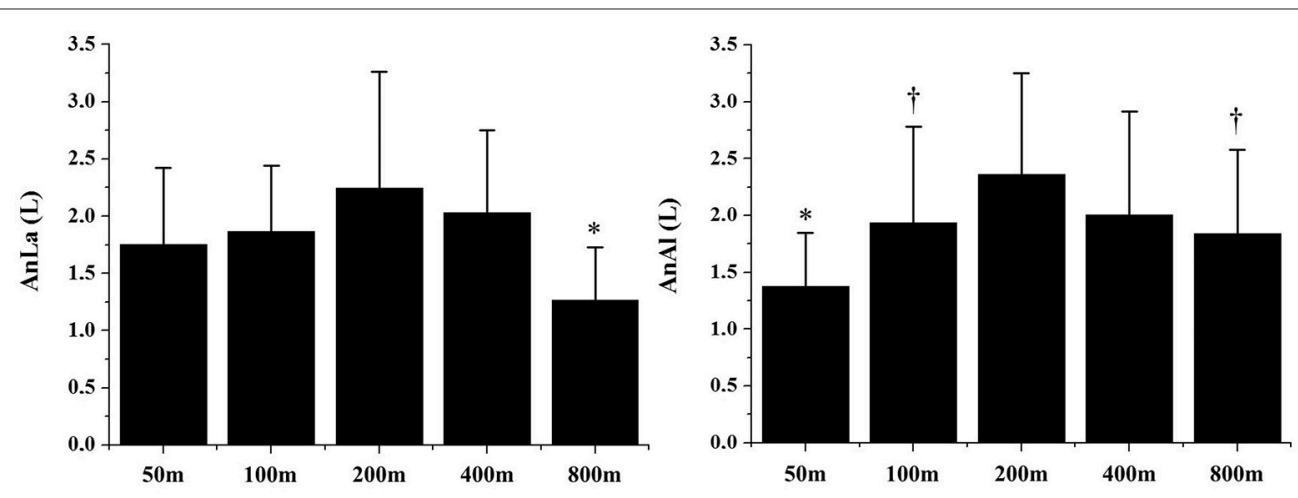

FIGURE 1 | Alactic (AnAl) and lactic (AnLa) anaerobic contributions in 50, 100, 200, 400, and $800 \mathrm{~m}$ performances. *Significant differences from other performances $(p>0.05) ;{ }^{\dagger}$ Significant differences from 200 to $400 \mathrm{~m}(p>0.05)$.

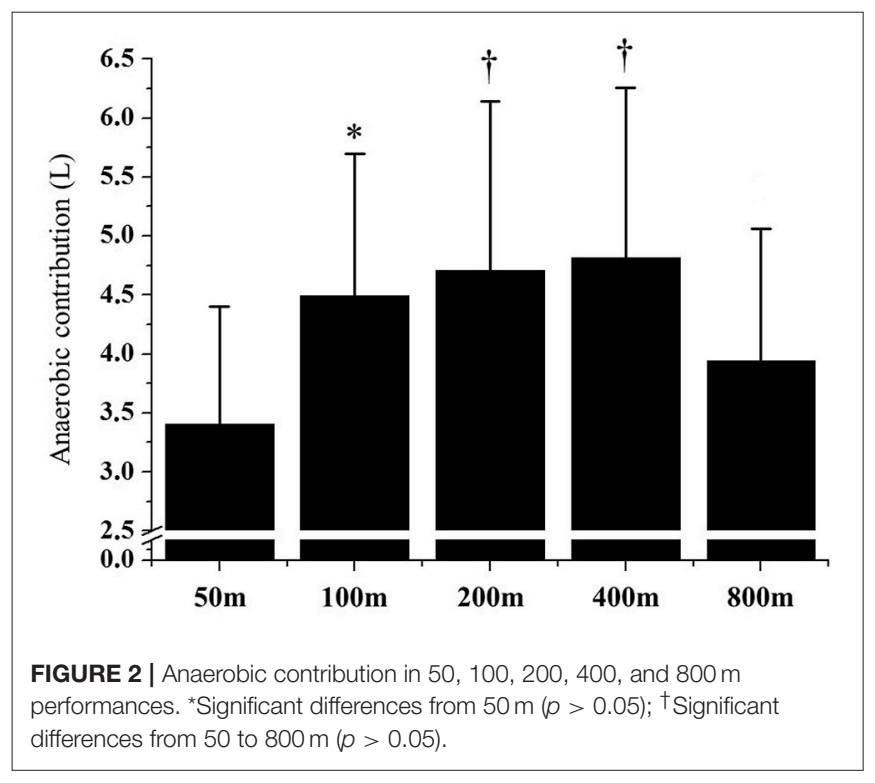

the analysis of the anaerobic contribution through net lactate accumulation and $\mathrm{VO}_{2}$ recovery has several strengths over the classic method proposed for AOD determination, such as: (i) analysis of lactic and alactic contribution separately, (ii) enables
TABLE 2 | Correlation coefficients between physiological parameters and performances at different distances.

\begin{tabular}{|c|c|c|c|c|c|}
\hline & \multicolumn{5}{|c|}{ Performances } \\
\hline & $50 \mathrm{~m}$ & $100 \mathrm{~m}$ & $200 \mathrm{~m}$ & $400 \mathrm{~m}$ & $800 \mathrm{~m}$ \\
\hline AnAl & $-0.64^{\star}$ & $-0.74^{*}$ & $-0.87^{\star}$ & -0.45 & -0.42 \\
\hline AnLa & $-0.77^{\star}$ & $-0.84^{\star}$ & $-0.79^{\star}$ & $-0.69^{\star}$ & -0.47 \\
\hline TAn & $-0.91^{\star}$ & $-0.85^{\star}$ & $-0.88^{\star}$ & $-0.68^{\star}$ & -0.53 \\
\hline
\end{tabular}

AnAl, Alactic anaerobic contribution; AnLa, Lactic anaerobic contribution; TAn, Total anaerobic contribution; *Significant correlations $(p<0.05)$.

undulations, turns, and side respiration, (iii) increases swimming speed, and (iv) is determined after one single effort.

The AnAl is determined through the product between the $\mathrm{VO}_{2}$ recovery amplitude and time constant (Margaria et al., 1933). We found that $50 \mathrm{~m}$ elicited significantly lower amplitude than other distances. This may be explained by the short effort time $(28.7 \pm 2.6 \mathrm{~s})$, which was too short to increase $\mathrm{VO}_{2}$ to the same level as the other distances. The time constant was significantly higher in $200 \mathrm{~m}$ than other distances, except for $50 \mathrm{~m}$. The amplitude of $200 \mathrm{~m}$ was similar to that observed by Sousa et al. (2013) in the same distance, however, the time constant was lower $(27.03 \pm 5.43 \mathrm{~s}$ vs. $48 \pm 12 \mathrm{~s}$, respectively). Thus, Sousa et al. (2013) observed an AnAl of $1.55 \pm 0.13 \mathrm{~L}$, 
which is significantly lower than observed in the present study. The likely reason for this difference is related to the use of a snorkel (Sousa et al., 2013), which may have reduced speed, increasing the aerobic contribution and decreasing the anaerobic contribution. This hypothesis is sustained by the similar results observed in AnAl contribution over $400 \mathrm{~m}$ in the study of KalvaFilho et al. (2015) (Amplitude: $3.0 \pm 1.3 \mathrm{~L}$ and Time constant: 0.9 $\pm 0.3 \mathrm{~s}$ ), since they also used free swimming performance, which does not limit the athletes mechanics and speed, increasing the anaerobic contribution.

The 200 and $400 \mathrm{~m}$ efforts elicited higher AnAl than the other distances. One possible reason for this result is that athletes perform 50 to $400 \mathrm{~m}$ performances above their critical speed, which does not enable recovery of creatine phosphate (Jones et al., 2008) and thus during 200 and $400 \mathrm{~m}$ athletes execute more turns at high intensity. It is important to note that, besides no statistical difference, the mean $400 \mathrm{~m} \mathrm{AnAl} \mathrm{was} \mathrm{lower}$ than $200 \mathrm{~m}$, which may indicate that, although athletes execute more turns at $400 \mathrm{~m}$ than at $200 \mathrm{~m}$, the turns are performed at lower intensity. The lower value observed at 50 and $100 \mathrm{~m}$ may also indicate that the time spent in high intensity effort may contribute to AnAl. Future studies may want to correlate $\mathrm{AnAl}$ and mechanical parameters related to turns and strokes to confirm this hypothesis.

In relation to AnLa, the baseline $\left[\mathrm{La}^{-}\right]$was similar between efforts. This result is important as AnLa takes into account the difference between peak and baseline [ $\mathrm{La}^{-}$] (di Prampero and Ferretti, 1999). In the present study, the $800 \mathrm{~m}$ presented lower values of AnLa than the other distances. These results can also be explained by the fact that the $800 \mathrm{~m}$ effort is performed at intensities close to critical speed, which reduces lactic anaerobic contribution. The accumulation found in the $800 \mathrm{~m}$ effort may be explained since athletes usually increase their speed at the end of the effort. Mauger et al. (2012) observed that swimmers use different pacing strategies during a $400 \mathrm{~m}$ effort, however, no studies have investigated whether these strategies may interfere in the aerobic or anaerobic contribution.

Total anaerobic contribution was higher at 100, 200, and $400 \mathrm{~m}$ than at the other distances, without differences between then. The TAn found in the present study for $100 \mathrm{~m}$ (55.12 \pm $\left.12.65 \mathrm{~mL} \cdot \mathrm{kg}^{-1}\right), 200 \mathrm{~m}\left(65.74 \pm 16.18 \mathrm{~mL} \cdot \mathrm{kg}^{-1}\right)$, and $400 \mathrm{~m}$ $\left(58.80 \pm 16.50 \mathrm{~mL} \cdot \mathrm{kg}^{-1}\right)$ were significantly higher than in the study of Reis et al. (2010a) (20.55 $\pm 7.41 \mathrm{~mL} \cdot \mathrm{kg}^{-1}, 17.53 \pm 13.53$ $\mathrm{mL} \cdot \mathrm{kg}^{-1}$, and $11.91 \pm 14.72 \mathrm{~mL} \cdot \mathrm{kg}^{-1}$, respectively. The main reason for this difference was the method used to estimate TAn. The Reis study used the AOD method to estimate anaerobic contribution, which requires a snorkel to analyze the differences between theoretical demand and aerobic demand. The mean speed during the 100,200, and $400 \mathrm{~m}$ efforts were lower in the study of Reis et al. (2010a) compared with the present study, even though their swimmers were only male and of a higher level. This may indicate that, when effort is performed with a snorkel, swimmers may be obligated to reduce speed, increasing the aerobic contribution and reducing the anaerobic contribution. These results highlight that the use of the backward extrapolation technique and net lactate appearance may be more feasible and present greater ecological validity than the accumulated oxygen deficit method to evaluate TAn in swimming. Furthermore, although other studies may want to compare TAn evaluated by accumulated oxygen deficit and the method used in the present study, due to this mechanical difference, comparison between them would be limited.

The possibility of determining AnAl and AnLa to estimate TAn is also important to verify their possible relation with swimming performance. Kalva-Filho et al. (2015) recently showed that TAn is highly associated with $400 \mathrm{~m}$ performance, however a relation of $\mathrm{AnAl}$ and AnLa with performance was not observed. We did not find any association of anaerobic contribution with $800 \mathrm{~m}$ performance which demonstrates that this distance is highly dependent on the aerobic metabolism. We found a significant association between AnAl and 50, 100 , and $200 \mathrm{~m}$ performances, without a relation with $400 \mathrm{~m}$. This clearly explains that this metabolism is determinant for short distance swimming performance. AnLa associates with 50 to $400 \mathrm{~m}$ performance, as well as TAn. It is interesting to note that, even though $50 \mathrm{~m}$ elicited lower values of TAn than 100,200 , and $400 \mathrm{~m}$, the relation of this variable with $50 \mathrm{~m}$ performance was stronger than the others $(r=-0.91$; Table 2), which indicates that the $50 \mathrm{~m}$ effort is highly dependent on the anaerobic contribution. Therefore, the use of the backward extrapolation technique together with the net lactate accumulation is a feasible method to calculate anaerobic contribution in swimming, and may be used during swimming training periodization in order to determine whether training stimulation are effective in elicit changes in these variables. Athletes and coaches may use these results during training prescription for different athletes, according to TAn, and, specially, AnAl and AnLa. Finally, if coaches wish to evaluate swimmers' maximal anaerobic contribution, they should use distances between 200 and $400 \mathrm{~m}$.

The strengths of the present study are: (i) swimmers were able to swim freely and perform they maximal effort without snorkel interference, and (ii) we evaluate TAn separately which gives an overview of energy system contribution during swimming. The main limitation of the present study is the use of both genders, since women seem to have lower anaerobic capacity than man (Hunter, 2014) thus, further studies should investigate the differences between men and women with a larger sample size. The evaluation of energy contribution during swimming distances provides a view of athlete's metabolic behavior during simulated trial, and since we did not control the strategy used during the effort-which might modify swimming TAn - the generalization to other athletes must be done with caution. Therefore, future researches may want to investigate whether TAn (i.e., AnAl and AnLa) changes with modification in swimming strategy among different swimming distances.

Considering this limitation, $\mathrm{AnAl}$ is higher in 200 and $400 \mathrm{~m}$ than the other distances, mainly due to the time spent at high speed, the AnLa is similar between the distances, however $800 \mathrm{~m}$ presented low values of lactate accumulation. The TAn is higher in 100,200 , and $400 \mathrm{~m}$ than the other distances, and coaches may want to select 200 and/or $400 \mathrm{~m}$ to evaluate the maximal anaerobic contribution of swimmers. Besides its feasibility, AnAl, 
AnLa, and TAn are highly associated with performance, and can be used in training routines, in order to assess modifications in TAn over the season.

\section{AUTHOR CONTRIBUTIONS}

EC: Data acquisition; data interpretation; manuscript writing. CK: Data interpretation; manuscript writing; Manuscript revision. RG: Data acquisition; manuscript writing. RB: Data

\section{REFERENCES}

Bertuzzi, R. C., Franchini, E., Ugrinowitsch, C., Kokubun, E., Lima-Silva, A. E., Pires, F. O., et al. (2010). Predicting MAOD using only a supramaximal exhaustive test. Int. J. Sports Med. 31, 477-481. doi: 10.1055/s-00301253375

Bertuzzi, R., Kiss, M., Damasceno, M., Oliveira, R., and Lima-Silva, A. (2015). Association between anaerobic components of the maximal accumulated oxygen deficit and 30-second Wingate test. Braz. J. Med. Biol. Res. 48, 261-266. doi: 10.1590/1414-431X20144043

Bonne, T. C., Lundby, C., Jorgensen, S., Johansen, L., Mrgan, M., Bech, S. R., et al. (2014). "Live High-Train High" increases hemoglobin mass in Olympic swimmers. Eur. J. Appl. Physiol. 114, 1439-1449. doi: 10.1007/s00421-014-2863-4

Campos, E., Kalva-Filho, C., Loures, J., Manchado-Gobatto, F., Zagatto, A., and Papoti, M. (2016). Comparison between peak oxygen consumption and its associated speed determined through an incremental test and a 400-m effort: implication for swimming training prescription. Sci. Sports 32, e37-e41. doi: 10.1016/j.scispo.2016.06.007

Costill, D. L., Kovaleski, J., Porter, D., Kirwan, J., Fielding, R., and King, D. (1985). Energy expenditure during front crawl swimming: predicting success in middle-distance events. Int. J. Sports Med. 6, 266-270. doi: $10.1055 / \mathrm{s}-2008-1025849$

di Prampero, P. E., and Ferretti, G. (1999). The energetics of anaerobic muscle metabolism: a reappraisal of older and recent concepts. Respir. Physiol. 118, 103-115. doi: 10.1016/S0034-5687(99)00083-3

Figueiredo, P., Zamparo, P., Sousa, A., Vilas-Boas, J. P., and Fernandes, R. J. (2011). An energy balance of the $200 \mathrm{~m}$ front crawl race. Eur. J. Appl. Physiol. 111, 767-777. doi: 10.1007/s00421-010-1696-Z

Hunter, S. K. (2014). Sex differences in human fatigability: mechanisms and insight to physiological responses. Acta Physiol. 210, 768-789. doi: 10.1111/apha.12234

Jalab, C., Enea, C., Delpech, N., and Bernard, O. (2011). [Dynamics of oxygen uptake during a $100 \mathrm{~m}$ front crawl event, performed during competition]. Appl. Physiol. Nutr. Metab. 36, 219-225. doi: 10.1139/h10-107

Jones, A. M., Wilkerson, D. P., DiMenna, F., Fulford, J., and Poole, D. C. (2008). Muscle metabolic responses to exercise above and below the "critical power" assessed using 31P-MRS. Am. J. Physiol. Regul. Integr. Comp. Physiol. 294, R585-R593. doi: 10.1152/ajpregu.00731.2007

Kalva, C. A., Zagatto, A. M., Araujo, M. I. C., Santiago, P. R. P., da Silva, A. S. R., Gobatto, C. A., et al. (2015). Relationship between aerobic and anaerobic parameters from 3-minute all-out tethered swimming and 400-m maximal front crawl effort. J. Strength Cond. Res. 29, 238-245. doi: 10.1519/JSC.0000000000000592

Kalva-Filho, C., Araújo, M., Silva, A., Gobatto, C., Zagatto, A., Gobbi, R., et al. (2016). Determination of VO2-intensity relationship and MAOD in tethered swimming. Int. J. Sports Med. 37, 687-693. doi: 10.1055/s-0035-1559696

Kalva-Filho, C., Campos, E., Andrade, V., Silva, A., Zagatto, A., Lima, M., et al. (2015). Relationship of aerobic and anaerobic parameters with $400 \mathrm{~m}$ front crawl swimming performance. Biol. Sport 32, 333-337. doi: $10.5604 / 20831862.1188611$

Lätt, E., Jürimäe, J., Haljaste, K., Cicchella, A., Purge, P., and Jürimäe, T. (2009). Longitudinal development of physical and performance parameters during biological maturation of young male swimmers. Percept. Mot. Skills 108, 297-307. doi: 10.2466/pms.108.1.297-307

Margaria, R., Edwards, H., and Dill, D. B. (1933). The possible mechanisms of contracting and paying the oxygen debt and the role of lactic acid in muscular contraction. Ame. J. Physiol. Legacy Content 106, 689-715. acquisition; data interpretation; manuscript revision. NA: Data acquisition; data interpretation. MP: Data analysis; manuscript revision; conception and study design; final approval of the version.

\section{FUNDING}

Fundação de Amparo à Pesquisa do Estado de São Paulo (FAPESP/ n 2013/15322-3).

Mauger, A. R., Neuloh, J., and Castle, P. C. (2012). Analysis of pacing strategy selection in elite 400-m freestyle swimming. Med. Sci. Sports Exerc. 44, 2205-2212. doi: 10.1249/MSS.0b013e3182604b84

Milioni, F., Malta, E. D. S., Rocha, L. G. S. D. A., Mesquita, C. A. A., de Freitas, E. C., and Zagatto, A. M. (2016). Acute administration of high doses of taurine does not substantially improve high-intensity running performance and the effect on maximal accumulated oxygen deficit is unclear. Appl. Physiol. Nutr. Metab. 41, 498-503. doi: 10.1139/apnm-2015-0435

Montpetit, R. R., Leger, L. A., Lavoie, J. M., and Cazorla, G. (1981). VO2 peak during free swimming using the backward extrapolation of the O2 recovery curve. Eur. J. Appl. Physiol. Occup. Physiol. 47, 385-391. doi: 10.1007/BF02332966

Pelayo, P., Alberty, M., Sidney, M., Potdevin, F., and Dekerle, J. (2007). Aerobic potential, stroke parameters, and coordination in swimming front-crawl performance. Int. J. Sports Physiol. Perform. 2, 347-359. doi: 10.1123/ijspp.2.4.347

Reis, V. M., Marinho, D., Policarpo, F., Carneiro, A., Baldari, C., and Silva, A. (2010a). Examining the accumulated oxygen deficit method in front crawl swimming. Int. J. Sports Med. 31, 421-427. doi: 10.1055/s-0030-1248286

Reis, V. M., Marinho, D. A., Barbosa, F. P., Reis, A. M., Guidetti, L., and Silva, A. J. (2010b). Examining the accumulated oxygen deficit method in breaststroke swimming. Eur. J. Appl. Physiol. 109, 1129-1135. doi: 10.1007/s00421-010-1460-4

Sousa, A., Figueiredo, P., Zamparo, P., Vilas-Boas, J. P., and Fernandes, R. J. (2013). Anaerobic alactic energy assessment in middle distance swimming. Eur. J. Appl. Physiol. 113, 2153-2158. doi: 10.1007/s00421-013-2646-3

Toussaint, H. M., and Hollander, A. P. (1994). Energetics of competitive swimming. Sports Med. 18, 384-405. doi: 10.2165/00007256-199418060-00004

Zagatto, A., Bertuzzi, R., Miyagi, W., Padulo, J., and Papoti, M. (2016a). MAOD determined in a single supramaximal test: a study on the reliability and effects of supramaximal intensities. Int. J. Sports Med. 37, 700-707. doi: 10.1055/s-0042-104413

Zagatto, A., de Mello, L. J., Papoti, M., and Beneke, R. (2016b). Energetics of table tennis and table tennis specific exercise testing. Int. J. Sports Physiol. Perform. 11, 1012-1017. doi: 10.1123/ijspp.2015-0746

Zagatto, A., Redkva, P., Loures, J., Kalva Filho, C., Franco, V., Kaminagakura, E., et al. (2011). Anaerobic contribution during maximal anaerobic running test: correlation with maximal accumulated oxygen deficit. Scand. J. Med. Sci. Sports 21, e222-e230. doi: 10.1111/j.1600-0838.2010.01258.x

Zamparo, P., Capelli, C., Cautero, M., and Di Nino, A. (2000). Energy cost of frontcrawl swimming at supra-maximal speeds and underwater torque in young swimmers. Eur. J. Appl. Physiol. 83, 487-491. doi: 10.1007/s004210000318

Zamparo, P., Capelli, C., and Pendergast, D. (2011). Energetics of swimming: a historical perspective. Eur. J. Appl. Physiol. 111, 367-378. doi: 10.1007/s00421-010-1433-7

Conflict of Interest Statement: The authors declare that the research was conducted in the absence of any commercial or financial relationships that could be construed as a potential conflict of interest.

Copyright (c) 2017 Campos, Kalva-Filho, Gobbi, Barbieri, Almeida and Papoti. This is an open-access article distributed under the terms of the Creative Commons Attribution License (CC BY). The use, distribution or reproduction in other forums is permitted, provided the original author(s) or licensor are credited and that the original publication in this journal is cited, in accordance with accepted academic practice. No use, distribution or reproduction is permitted which does not comply with these terms. 